\title{
Cetylpyridinium-chloride (CPC) and Miramistin (MST) compared to established antiseptics under protein challenge in-vitro - evaluating alternative agents for wound cleansing
}

Julian-Dario Rembe ( $\sim$ julian-dario.rembe@uni-wh.de)

Institute for Translational Wound Research, Centre for Biomedical Education and Research (ZBAF), Universitat Witten/Herdecke https://orcid.org/0000-0002-5176-6941

\section{Vivian-Denise Thompson}

Institute for Translational Wound Research, Centre for Biomedical Education and Research (ZBAF), Witten/Herdecke University

\section{Nina Hauer}

Institute for Translational Wound Research, Centre for Biomedical Education and Research (ZBAF), Witten/Herdecke University

\section{Ewa Klara Klara Stuermer}

Institute for Translational Wound Research, Centre for Biomedical Education and Research (ZBAF), Witten/Herdecke University

Research article

Keywords: cetylpyridinium-chloride, miramistin, antimicrobials, antiseptics, wound healing, wound infection

Posted Date: April 24th, 2019

DOI: https://doi.org/10.21203/rs.2.9330/v1

License: (1) This work is licensed under a Creative Commons Attribution 4.0 International License. Read Full License 


\section{Abstract}

Background: Due to rising numbers microbial resistance to established antibiotics and first described tolerance developments for local wound antimicrobials a continuous need for alternative antimicrobial agents exists. Due to complex conditions in the microenvironment of especially chronic wounds, such as high protein levels, novel antimicrobials need to meet advanced requirements. Aim: Compare the antimicrobial efficacy of Cetylpiridinium-chloride (CPC) and miramistin (MST) to established antimicrobials under protein-challenge in-vitro. Methods: Antimicrobial activity of octenidindihydrochloride, povidon-iodine, polyhexamethylene-biguanide hydrochloride, chlorhexidine, cetylpiridinium-chloride and Miramistin after $0.5,1,3,5$ and 10 min of exposure against S. aureus, P. aeruginosa, E. coli, E. faecium and C. albicans was tested, using a quantitative suspension method with either $0.3 \%$ or $3 \%$ bovine albumin challenge, based on DIN EN 13727 ('Chemical disinfectants and antiseptics - Quantitative suspension test for the evaluation of bactericidal activity in the medical area Test method and requirements (phase 2, step 1)'). Results: CPC and MST demonstrated no inferiority to the established agents in-vitro. Especially CPC showed equal reduction rates as octenidin and povidoniodine and achieved significantly higher reduction rates within shorter exposure times than polyhexanide and chlorhexidine $(p \leq 0.01)$ for $S$. aureus, P. aeruginosa, E. faecium and C. albicans. Both agents demonstrated no significant loss of efficacy under high protein-challenge ( $3 \%$ albumin). Conclusion: In terms of antimicrobial activity cetylpyridinium-chloride and miramistin proved to be at least equally effective as established agents. No protein error was detected in the tested concentrations. More complex in-vitro assays and comprehensive in-vivo and clinical studies will be needed to determine their clinical value.

\section{Background}

Wound infection remains a major issue and challenge for health-care providers and patients. An increasingly elderly patient population is at higher risk of developing surgical site infections (SSI) as well as chronic wounds due to predisposing factors such as diabetes, peripheral arterial disease or chronic venous insufficiency. [1] Chronic wounds are generally considered to be at least colonized by microorganisms, whereby recent studies stated up to $78 \%$ to be challenged by biofilm formation [2]. Surgical site infections (SSI) account for on average $20 \%$ of hospital-acquired infections in Europe. [3-6] Antimicrobial wound cleansing and local antisepsis are key factors in the treatment of acute and chronic wound infections. Octenidin-dihydrochloride (OCT), povidon-iodine (PVP-I), polyhexamethylene-biguanide hydrochloride (PHMB; polyhexanide) and chlorhexidine (CHX) represent the main antimicrobial agents used in wound management. So far no single antimicrobial has proven to be generally superior regarding treatment of local wound infection or promotion of wound healing. [7, 8] [9] With adverse effects on essential cells for skin regeneration, such as fibroblasts and keratinocytes, reported for each agent [10, 11], antibiotic resistance on the rise [12] and first reports of developing tolerance to local antiseptics [13, 14], investigations into alternative antimicrobial agents with comparable efficacy and low cytotoxic impact to human skin cells are necessary. 
Two potential alternatives are the quaternary ammonium compounds Cetylpyridinium-chloride (CPC) and Miramistin (MST), belonging to the family of cationic surface-active agents. Based on first promising results regarding antimicrobial efficacy and cytotoxicity to human cells in-vitro [15], this study aimed to compare MST and CPC to OCT, PVP-I, PHMB and CHX in challenging conditions simulating a high-protein wound environment, with short exposure times (as in clinical practice) against common wound pathogens (Staphylococcus aureus, Escherichia coli, Pseudomonas aeruginosa, Enterococcus faecium and Candida albicans).

\section{Methods}

\section{Preparation of antiseptic solutions}

Octenidin-dihydrochloride (Octenisept®; OCT, 0.1\%; Schülke \& Mayr GmbH, Norderstedt, Germany) and povidone-iodine (Betaisodona ${ }^{\circledR}$; PVP-I, 10\%; Mundipharma GmbH, Limburg, Germany) were used as readily available customary products of everyday clinical use (concentrations as indicated by manufacturer).

Polyhexamethylene-biguanide (PHMB, 20\%; Bonding, Shanghai, China) and chlorhexidine (CHX, 2\%; Carl Roth, Karlsruhe, Germany) were prepared in distilled water to reach desired final test concentrations of $0.02 \%(\mathrm{v} / \mathrm{v} ; \mathrm{PHMB})$ and $0.2 \%(\mathrm{v} / \mathrm{v} ; \mathrm{CHX})$ in compliance with previously published studies and available wound cleansing products.

Cetylpyridinium-chloride (CPC; Sigma-Aldrich, Schnelldorf, Germany) and Miramistin (MST; Farmhim, Shostka, Ukraine) were purchased as powders and also prepared in distilled water to reach best suited final test concentrations of $0.5 \%(\mathrm{w} / \mathrm{v} ; \mathrm{CPC})$ and $0.05 \%(\mathrm{w} / \mathrm{v} ; \mathrm{MST})$ according to previous experiments [15]. An overview as well as specifications for the tested products/substances is provided in table 1.

\section{Test organisms and nutrient solutions}

In this work, Pseudomonas aeruginosa (DSM-939), Staphylococcus aureus (DSM-799), Escherichia coli (DSM-11250), Enterococcus faecium (DSM-2146) and Candida albicans (DSM-1386; all DSMZ, Braunschweig, Germany) were used as bacterial test strains. As nutrient solution sterile casein/soy peptone broth (CSB) was prepared consisting of $15 \mathrm{mg} \mathrm{ml}-1$ casein peptone, $5 \mathrm{mg} \mathrm{ml}-1$ soy peptone and $5 \mathrm{mg} \mathrm{ml}-1$ sodium chloride diluted in distilled water. The $\mathrm{pH}$ value was adjusted to 7.2 using $5 \mathrm{~N}$ sodium hydroxide (all AppliChem, Darmstadt, Germany). One fresh colony of each bacterial strain was added to $50 \mathrm{ml} \mathrm{CSB}$ and incubated over night at $37^{\circ} \mathrm{C}$ under aerobic conditions and agitation. Bacterial test solutions were adjusted using a spectrophotometer to result in initial counts of $\sim 1.5-3.0 \times 108 \mathrm{CFU}$ ml1. Fungal test solutions were prepared in the same manner using malt/soy peptone broth (MEB) and malt agar (MEA). Initial microbial CFU ml-1 counts were controlled by spreading serial dilutions of untreated microbial test solutions of each experiment onto agar plates allowing exact calculations of reduction rates. 


\section{Challenge and neutralisation solutions}

To simulate a challenging wound environment and determine possible decrease in efficacy of the tested antiseptics especially under high-protein conditions, bovine albumin (Carl Roth, Karlsruhe, Germany) was added to the experimental setup (as recommended in the standard DIN EN 13727 by the german institute for standardization (DIN)). [16] Challenge solutions contained either $3 \mathrm{mg} \mathrm{ml}-1(0.3 \%)$ or $30 \mathrm{mg} \mathrm{ml}-1$ (3\%) albumin and were prepared using an autoclaved casein/natriumchloride solution dissolved in distilled water. The challenge solution was subsequently aliquoted and stored at $-18^{\circ} \mathrm{C}$ until usage.

To prevent further antimicrobial activity beyond sampling time points, a neutralisation solution was used in accordance with DIN EN 13727, comprising $3 \mathrm{~g} \mathrm{l-1}$ sodium thiosulfate, $30 \mathrm{~g} \mathrm{l}-1$ saponine, $30 \mathrm{~g} \mathrm{l}-1$ polysorbate 80 (Tween 80), $3 \mathrm{~g} \mathrm{l-1}$ lecithin, $1 \mathrm{~g} \mathrm{l-1} \mathrm{L-histidine} \mathrm{and} 1 \mathrm{~g} \mathrm{l-1} \mathrm{L-cysteine} \mathrm{(all} \mathrm{Carl} \mathrm{Roth,}$ Karlsruhe, Germany) diluted in distilled water and autoclaved for sterility. Both, challenge and neutralization solution, were individually validated regarding their purpose and showed no antimicrobial effects of its own.

\section{Quantitative suspension method}

The test method for evaluation of antimicrobial efficacy was based on DIN EN 13727 and slightly adjusted to fit the purpose. [16] Briefly, $1 \mathrm{ml}$ microbial and $1 \mathrm{ml}$ challenge solution ( $0.3 \%$ or $3 \%$ bovine albumin) were carefully mixed for two minutes and $8 \mathrm{ml}$ of antimicrobial test solution was added. After $0.5,1,3,5$ and 10 min of exposure $1 \mathrm{ml}$ of the resulting solution was transferred into the prepared neutralisation solution ( $8 \mathrm{ml}$ neutralizer and $1 \mathrm{ml}$ distilled water) and continuously agitated. After $10 \mathrm{sec}$, $0.5 \mathrm{ml}$ was again transferred into $4.5 \mathrm{ml}$ neutralisation solution to thoroughly block further antimicrobial activity. Subsequently, this sample was serially tenfold diluted in either CSB (for bacteria) or MEB (for yeast), $25 \mathrm{I}$ of every dilution step were seeded on either CSA or MEA plates and incubated at $37^{\circ} \mathrm{C}$ under aerobic conditions overnight. Surviving microorganisms (in CFU ml-1) were counted. Experiments were performed threefold at different times and in duplicates for each tested antiseptic and microorganism challenged with either $3 \mathrm{mg} \mathrm{ml}-1$ or $30 \mathrm{mg} \mathrm{ml}-1$ albumin solution.

\section{Statistical analysis}

Reduction rates were calculated for all tested antimicrobials (in $\Delta \log 10 \mathrm{CFU} \mathrm{ml}-1$ ). For bacteria, a high antimicrobial efficacy (reducing at least $99.999 \%$ of initial bacterial counts) is indicated by a reduction of at least $5 \log 10$ reduction steps within $1 \mathrm{~min}$ as specified in DIN EN 13727. [16] For yeast the cut-off for a high efficacy is considered at least $4 \log 10$ reduction steps as specified in DIN EN 13624. Mean values and SEM were calculated and differences considered statistically significant at $p<0.05$.

Statistical evaluations of the antimicrobial efficacy were performed using two-way repeated measures ANOVA with Tukey's HSD test as post-hoc analysis for multiple comparisons. The statistic package GraphPad PRISM (GraphPad Software, Inc., La Jolla, United States of America) was used for statistical analysis. 


\section{Results}

\section{Antimicrobial efficacy on tested pathogens}

An overview on the reduction rates (in $\triangle \log 10 \mathrm{CFU}$ ml-1 \pm SEM reduction steps compared to initial CFU $\mathrm{ml}-1$ ) of the tested antimicrobial agents is given in table 2 .

Octenidin-dihydrochloride/phenoxyethanol (OCT) and povidone-iodine (PVP-I)

OCT and PVP-I achieved significant and complete eradication against all tested microorganism within 0.5 min of exposure $(p<0.0001)$. Increased protein challenge of $0.3 \%$ or $3 \%$ albumin did not exert a negative effect on their antimicrobial activity (fig. $1-5$ ).

Polyhexamethylene-biguanide hydrochloride (PHMB)

PHMB showed to be less effective in the conducted experiments. After 0.5 min of exposure with $0.3 \%$ protein challenge, PHMB achieved significantly lower reduction rates compared to other tested antimicrobials, such as OCT or PVP-I ( $p \leq 0.01)$. A significant and strong antimicrobial efficacy $(>5 \log 10$ steps within $1 \mathrm{~min} ; p<0.0001)$ was achieved against all investigated microorganism, but for complete eradication extended exposure times were necessary: $3 \mathrm{~min}$ for $S$. aureus (fig. 1) and P. aeruginosa (fig. 3) and 5 min for $E$. faecium (fig. 4) and C. albicans (fig. 5). Only against E. coli (fig. 2) PHMB did not achieve complete eradication within the investigated exposure time (maximum reduction: $7.38 \pm 0.81$ ).

Under higher protein-challenge (3\% albumin), PHMB showed comparable results, achieving complete eradication for all tested microorganism except for E. coli (fig. 2). Longer exposure times were necessary under increased protein-challenge, especially to eradicate $S$. aureus and $C$. albicans ( $10 \mathrm{~min}$ for both) and reduction rates were lower at tested time-points compared to $0.3 \%$ protein challenge, yet not statistically significant (fig. 1 and 5). Against P. aeruginosa and E. faecium, PHMB achieved complete eradication within 3 min (fig. 3 and 4).

\section{Chlorhexidine $(\mathrm{CHX})$}

$\mathrm{CHX}$ challenged with $0.3 \%$ albumin achieved complete eradication of E.coli (within $0.5 \mathrm{~min} ; p<0.0001$, fig. 2), P.aeruginosa (within 1 min; $p<0.0001$, fig. 3) and E. faecium (within 5 min; $p<0.0001$, fig. 4) after varying exposure times. Against $S$. aureus and $C$. albicans $\mathrm{CHX}$ did not manage complete eradication under $0.3 \%$ challenge within the tested exposure time, but achieved significant and required reduction rates (> $5 \log 10$ steps within 1 min; $p<0.0001$, fig. 1 and 5). This standard criterion was not met for $E$. faecium, despite a complete eradication (table 1 and fig. 4).

Under $3 \%$ protein challenge $\mathrm{CHX}$ achieved comparable results, demonstrating no significant difference in efficacy between a $0.3 \%$ and $3 \%$ challenge. Only for $S$. aureus an extended exposure time was needed to achieve the required cut off ( 3 min; 5.991.99, fig. 1). Also, compared to the lower challenge, $\mathrm{CHX}$ achieved a complete eradication of $C$. albicans within 3 min of exposure (fig. 5). 
Regardless of the protein challenge, CPC achieved a strong antimicrobial efficacy, as indicated by the standard, within $0.5 \mathrm{~min}$ of exposure against each tested microorganism. Complete eradication was achieved within $0.5 \mathrm{~min}$ against $S$. aureus, $E$. coli and $E$. faecium $(p<0.0001 ;$ fig. 1,2 and 4$)$. For $C$. albicans under $0.3 \%$ challenge (fig. 5 ) and $P$. aeruginosa under $3 \%$ challenge (fig. 3 ), 1 min of exposure was needed for complete eradication.

\section{Miramistin}

Against E. coli and E. faecium MST managed complete reduction within 0.5 min under lower ( $0.3 \%)$ as well as higher (3 \%) protein challenge (fig. 2 and 4). Generally, MST met the criteria set by the standards (> 5 log10 steps within $1 \mathrm{~min}$ ) for all tested microorganism.

Challenged with $0.3 \%$ albumin, MST managed complete reduction of $S$. aureus and $C$. albicans within 3 min (fig. 1 and $5 ; p<0.0001$ ), while for $P$. aeruginosa 5 min of exposure were needed (fig. $3 ; p<0.0001$ ).

Under higher protein challenge (3\%), results were similar compared to $0.3 \%$ challenge with MST achieving complete eradication of $S$. aureus and $C$. albicans within 3 min (fig. 1 and $5 ; p<0.0001$ ). For $P$. aeruginosa only 1 min of exposure was needed under $3 \%$ albumin challenge (fig $3 ; p<0.0001$ ).

\section{Discussion}

Due to the globally rising challenge of antibiotic resistance and tolerance development in microorganim [12], advancements to counteract such challenges and investigations into new local antimicrobial agents are indispensable. Based on previously published data on the basic efficacy of CPC and MST as alternative antimicrobials and their cytotoxicity to human skin cells (keratinocytes and fibroblasts) [15], as relevant side-effects in wound management, this study extended the previous work to evaluate CPC and MST compared to established antiseptics. To especially account for the high-protein environment of wounds, bovine albumin was used in the experimental setup as a challenge substance to evaluate the protein-error of the tested agents, capable of reducing an antimicrobials efficacy. $[17,18]$

As expected, the established agents OCT, PVP-I, CHX and PHMB managed the broad range of tested microorganism well and achieved a high antimicrobial efficacy, as reported in several previous studies $[11,19,20]$. All investigated agents, except PHMB and CHX, achieved the required reduction of $>5 \log 10$ phases within $1 \mathrm{~min}$ of exposure demanded by the international standard and managed complete eradication within the investigated time-course. Even though PHMB and $\mathrm{CHX}$ failed complete eradication in individual cases, they demonstrated an overall strong antimicrobial efficacy. PHMB only failed to completely eradicate $E$. coli in this study (fig. 2), while $\mathrm{CHX}$ demonstrated weaknesses against $S$. aureus and $C$. albicans (fig. 1 and 5). Of the established antimicrobials, OCT and PVP-I proved to be most effective, followed by PHMB and CHX. 
The alternative agents investigated, especially CPC, demonstrated an antimicrobial efficacy comparable to the most effective established antiseptics OCT and PVP-I within the tested exposure times (fig. 1-5). Only in one case (against $P$. aeruginosa under $3 \%$ challenge), CPC needed insignificantly longer to achieve complete eradication ( $1 \mathrm{~min}$ instead of $0.5 \mathrm{~min}$ ). In all other experiments, CPC performed as well as OCT or PVP-I regardless of the administered protein challenge. Especially under high protein challenge $(3 \%)$ within the first 1-3 min of exposure, CPC demonstrated significantly higher and faster reduction rates than PHMB and CHX (fig. 1-5; $p<0.0001$ ). MST overall showed a slightly lower efficacy and partly longer exposure times than OCT, PVP-I and CPC, yet only statistically significant against $S$. aureus $(p<0.0001)$ and $P$. aeruginosa $(p<0.01)$ within the first 0.5 min. Compared to PHMB and CHX, MST proved significantly more effective against most microorganisms $(p<0.01)$.

As described in various studies, several antiseptics show a significant loss of efficacy under high-protein challenge. The local wound microenvironment contains about 3 to $5 \%$ total protein in acute and chronic wounds. [21,22] When assessing antimicrobial substances this influencial factor needs to be taken into account to approximate their efficacy in the in-vivo setting. Kapalschinski et al. demonstrated, that the addition of $0.3 \%$ albumin in in-vitro settings already significantly reduces the antiseptic potency of PHMB, OCT and PVP-I depending on the antiseptics concentration and that with rising protein concentration the antimicrobial efficacy is further diminished. $[17,18]$ These results are in line with our previous investigations of antiseptic wound dressings, demonstrating a significant dose-dependent loss of efficacy for some silver- and PHMB-containing foam dressings challenged with human acute wound fluid (median protein content of 3.9\%) [23], as well as the results in this study: especially the biguanides PHMB and $\mathrm{CHX}$, to some extend, demonstrate differences in performance under $0.3 \%$ and $3 \%$ albumin challenge (e.g. against $S$. aureus (fig. 1)). The fact, that this solely occurs for PHMB and CHX without statistical significance, presumably arises from the differences in evaluated concentrations. The reported significant results of Kapalschinski et al. became especially apparent in lower concentrations of the tested antiseptics (e.g. $0.005 \%$ PHMB), while the concentrations of other publications and commercially available products is usually higher $(0.02 \%, 0.04 \%$ or higher) and less affected by the investigated amounts of protein. Nevertheless, $0.02 \%$ PHMB yielded comparable decreases in reduction rates $(\sim 1$ $\log 10$ difference between $0.3 \%$ and $3 \%$ albumin) against $S$. aureus in both studies. The tested concentrations of OCT and PVP-I showed no reduction in efficacy under high protein challenge, which is also in line with previously reported results. [17] The alternatives of interest, CPC and MST, demonstrated varying results: while the efficacy of CPC remained unaltered under higher protein challenge, MST showed a slight decrease in efficacy, yet only against $S$. aureus within the first $0.5 \mathrm{~min}$ of exposure $(\sim 3$ log10 reductions; fig. 1). Therefore, in this study CPC, OCT and PVP-I showed no, MST a slight and CHX as well as PHMB a comparable higher protein-error in the tested concentrations. Generally, the reported results indicate a certain extend of protein error in a complex high-protein microenvironment of the wound, depending on the concentration of the used antimicrobial, the amount of challenging total protein as well as the class of antimicrobials. For biguanides such as $\mathrm{CHX}$ and PHMB high protein challenge seems to be more relevant than for other antimicrobials. Especially in the case of PHMB the results have 
to be interpreted with regard to the used lower antimicrobial concentration available as commercial product $(0.02 \%)$, so that higher concentrations of PHMB are unlikely to yield a relevant protein error.

In light of the presented results, compared to established antimicrobials, the general antimicrobial efficacy of CPC and MST, as well as challenged with a higher protein concentration (3\%), proved to be at least equal, even superior in certain cases, against a broad range of microorganisms encountered in wound management. Especially CPC demonstrated the same efficacy as the highly potential antiseptics OCT and PVP-I with no protein error. MST proved to be only slightly less effective, yet still significantly more effective than the biguanides PHMB and CHX. Additionally, in the context of biocompatibility to human wound cells, which should be given equal consideration as previously described by Mueller \& Kramer [20], the alternative agents demonstrated promising toxicity profiles in earlier published in-vitro evaluations. [15] For OCT and PVP-I severe cytotoxic effects on human keratinocytes and fibroblasts invitro have been reported [20], even stating dilutions of commercially available products as low as $12.5 \%$ (OCT) and $7.5 \%$ (PVP-I) to reduce cell viability and proliferation of fibroblasts and keratinocytes to $0 \%$ [24]. MST $(0.05 \%)$ in comparison only demonstrated a reduction of cell vitality to about $30 \%$ for keratinocytes and fibroblasts in a previous study [15], being still highly toxic but more biocompatible than OCT or PVP-I. CPC on the contrary proved even less toxic, showing only a $50 \%$ reduced cell vitality within 60 min of exposure [15], ranging its toxicity towards human skin cells considerably lower than OCT or PVP-I while achieving the same antimicrobial efficacy.

\section{Conclusion}

Overall, CPC and MST feature a high potential as alternative antimicrobials based on their in-vitro efficacy profiles compared to established antiseptics. Especially CPC proved to be at least equally, in case of PHMB and CHX even significantly $(p<0.0001)$ more effective against tested microorganisms than established antiseptics. Neither CPC nor MST suffered a significant loss in efficacy under challenging high-protein ( $3 \%$ albumin) conditions. Considering that the here tested concentration of CPC $(0.5 \%)$ also demonstrated lower toxic side-effects in earlier studies than those reported for OCT anf PVP-I, especially CPC should be further persecuted in more complex in-vitro and comprehensive in-vivo studies, as a potential new antimicrobial agent in wound management.

\section{List Of Abbreviations}

CFU - Colony forming unit

$\mathrm{CHX}$ - Chlorhexidine

CPC - Cetylpyridinium chloride

CSA - casein/soy peptone agar

CSB - casein/soy peptone broth 
DIN - Deutsches Institut für Normung (German institute for standardization)

DSMZ - Deutsche Sammlung von Mikroorganismen und Zellkulturen (German Collection of Microorganisms and Cell Culture)

HAI - Hospital-acquired Infection

MEA - malt/soy peptone agar

MEB - malt/soy peptone broth

MST - Miramistin

OCT - Octenidin

PHMB - Polyhexamethylene-biguanide hydrochloride

PVP-I - Povidone-lodine

RKI - Robert Koch-Institute

SSI - surgical-site infection

$\mathrm{v} / \mathrm{v}$ - volume per volume percentage

$\mathrm{w} / \mathrm{v}$ - weight per volume percentage

\section{Declarations}

Ethics approval and consent to participate

Not applicable

Consent for publication

Not applicable

\section{Availability of data and materials}

The datasets used and/or analysed during the current study are available from the corresponding author on reasonable request.

\section{Competing interests}

The authors declare, that they have no competing interests.

Funding 
The presented work was exclusively supported by internal funding of the University of Witten/Herdecke. The department for Translational Wound Research is generally an endowed chair funded by Dr. Ausbüttel \& Co. GmbH. For the presented work no benefit in any way, directly as well as indirectly, has been or will be received.

\section{Authors contributions}

JDR and EKS designed the study. VT and NH performed the experiments. JDR and VT performed statistical analysis and designed the figures. JDR, VT and EKS drafted the manuscript. All authors read and approved the final manuscript.

\section{Acknowledgements}

The authors would like to thank Univ.-Prof. Dr. rer. nat. Frank Krummenauer, Head of the Institute for Medical Biometry and Epidemiology (IMBE) at the Faculty of Health, Witten/Herdecke University and especially his research associate Sabrina Tulka, M.Sc., for their advice and support regarding statistical analysis.

\section{References}

1. Hachenberg T, Senturk M, Jannasch O, Lippert H. [Postoperative wound infections. Pathophysiology, risk factors and preventive concepts]. Anaesthesist. 2010;59(9):851-66; quiz 67-8.

2. Malone M, Bjarnsholt T, McBain AJ, James GA, Stoodley P, Leaper $D$, et al. The prevalence of biofilms in chronic wounds: a systematic review and meta-analysis of published data. J Wound Care. 2017;26(1):205 .

3. Werdin F, Tennenhaus M, Schaller HE, Rennekampff HO. Evidence-based management strategies for treatment of chronic wounds. Eplasty. 2009;9:e19.

4. Zarb P, Coignard B, Griskeviciene J, Muller A, Vankerckhoven V, Weist K, et al. The European Centre for Disease Prevention and Control (ECDC) pilot point prevalence survey of healthcare-associated infections and antimicrobial use. Euro Surveill. 2012;17(46).

5. ESPAUR. English Surveillance Programme for Antimicrobial Utilisation and Resistance (ESPAUR) Report 2017. 2017.

6. NRZ. [German national point-prevalence survey on nosocomial infections and antibiotic utilisation 2016]. 2016.

7. Norman G, Dumville JC, Moore ZE, Tanner J, Christie J, Goto S. Antibiotics and antiseptics for pressure ulcers. Cochrane Database Syst Rev. 2016;4:CD011586. 
8. Wu L, Norman G, Dumville JC, O'Meara S, Bell-Syer SE. Dressings for treating foot ulcers in people with diabetes: an overview of systematic reviews. Cochrane Database Syst Rev. 2015(7):CD010471.

9. Lachapelle JM. A comparison of the irritant and allergenic properties of antiseptics. Eur J Dermatol. 2014;24(1):3-9.

10. Hirsch T, Koerber A, Jacobsen F, Dissemond J, Steinau HU, Gatermann S, et al. Evaluation of toxic side effects of clinically used skin antiseptics in vitro. J Surg Res. 2010;164(2):344-50.

11. Hirsch T, Seipp HM, Jacobsen F, Goertz O, Steinau HU, Steinstraesser L. Antiseptics in surgery. Eplasty. 2010;10:e39.

12. Ventola CL. The antibiotic resistance crisis: part 1: causes and threats. P T. 2015;40(4):277-83.

13. Bowler PG. Antibiotic resistance and biofilm tolerance: a combined threat in the treatment of chronic infections. J Wound Care. 2018;27(5):273-7.

14. Percival SL, Salisbury AM, Chen R. Silver, biofilms and wounds: resistance revisited. Crit Rev Microbiol. 2019:1-15.

15. Fromm-Dornieden C, Rembe JD, Schafer N, Bohm J, Stuermer EK. Cetylpyridinium chloride and miramistin as antiseptic substances in chronic wound management - prospects and limitations. $\mathrm{J}$ Med Microbiol. 2015;64(Pt 4):407-14.

16. DIN. EN 13727:2012+A1:2013 - Chemical disinfectants and antiseptics - Quantitative suspension test for the evaluation of bactericidal activity in the medical area - Test method and requirements (phase 2, step 1); German version. 2013.

17. Kapalschinski N, Seipp HM, Kuckelhaus M, Harati KK, Kolbenschlag JJ, Daigeler A, et al. Albumin reduces the antibacterial efficacy of wound antiseptics against Staphylococcus aureus. J Wound Care. 2017;26(4):184-7.

18. Kapalschinski N, Seipp HM, Onderdonk AB, Goertz O, Daigeler A, Lahmer A, et al. Albumin reduces the antibacterial activity of polyhexanide-biguanide-based antiseptics against Staphylococcus aureus and MRSA. Burns. 2013;39(6):1221-5.

19. Hirsch T, Limoochi-Deli S, Lahmer A, Jacobsen F, Goertz O, Steinau HU, et al. Antimicrobial activity of clinically used antiseptics and wound irrigating agents in combination with wound dressings. Plast Reconstr Surg. 2011;127(4):1539-45.

20. Muller G, Kramer A. Biocompatibility index of antiseptic agents by parallel assessment of antimicrobial activity and cellular cytotoxicity. J Antimicrob Chemother. 2008;61(6):1281-7. 
21. James TJ, Hughes MA, Cherry GW, Taylor RP. Simple biochemical markers to assess chronic wounds. Wound Repair Regen. 2000;8(4):264-9.

22. Thamm OC, Koenen P, Bader N, Schneider A, Wutzler S, Neugebauer EA, et al. Acute and chronic wound fluids influence keratinocyte function differently. Int Wound J. 2015;12(2):143-9.

23. Rembe JD, Fromm-Dornieden C, Bohm J, Stuermer EK. Influence of human acute wound fluid on the antibacterial efficacy of different antiseptic polyurethane foam dressings: An in vitro analysis. Wound Repair Regen. 2018;26(1):27-35.

24. Hirsch T, Jacobsen F, Rittig A, Goertz O, Niederbichler A, Steinau HU, et al. [A comparative in vitro study of cell toxicity of clinically used antiseptics]. Hautarzt. 2009;60(12):984-91.

\section{Tables}

Table 1 - Specifications on test substances. Information have been obtained from the manufacturer. The investigated antimicrobial agent/product is stated in the first row, followed by corresponding chemical group, manufacturer, composition as well as final test concentration of the antimicrobial agent tested in this study (commercially available products were used in undiluted formulation as provided by manufacturer). 


\section{Table 1}

\begin{tabular}{|c|c|c|c|c|}
\hline $\begin{array}{l}\text { Antimicrobial agent } \\
\text { (commercial product) }\end{array}$ & $\begin{array}{l}\text { Chemical } \\
\text { group }\end{array}$ & Manufacturer & Composition & $\begin{array}{l}\text { Final test } \\
\text { concentration }\end{array}$ \\
\hline $\begin{array}{l}\text { Octenidin- } \\
\text { dihydrochloride } \\
\left.\text { (Octenisept }{ }^{\circledR}\right)\end{array}$ & $\begin{array}{l}\text { Bis- } \\
\text { pyridinamine }\end{array}$ & $\begin{array}{l}\text { Schülke \& } \\
\text { Mayr GmbH, } \\
\text { Norderstedt, } \\
\text { Germany }\end{array}$ & $\begin{array}{l}0.1 \% \text { octenidin- } \\
\text { dihydrochloride with } 2 \% \\
\text { phenoxyethanol in } \\
100 \mathrm{ml} \text { aqueous } \\
\text { solution }\end{array}$ & $0.1 \%$ \\
\hline $\begin{array}{l}\text { Polyhexamethylene- } \\
\text { biguanide } \\
\text { hydrochloride }\end{array}$ & $\begin{array}{l}\text { Polymeric } \\
\text { biguanide }\end{array}$ & $\begin{array}{l}\text { Bonding, } \\
\text { Shanghai, } \\
\text { China }\end{array}$ & $\begin{array}{l}20 \% \\
\text { polyhexamethylene- } \\
\text { biguanide hydrochloride } \\
\text { stock solution in } \\
\text { distilled water }\end{array}$ & $0.02 \%$ \\
\hline $\begin{array}{l}\text { Chlorhexidindigluconat } \\
\text {-solution } 2 \%\end{array}$ & $\begin{array}{l}\text { Bis- } \\
\text { biguanide }\end{array}$ & $\begin{array}{l}\text { Carl Roth, } \\
\text { Karlsruhe, } \\
\text { Germany }\end{array}$ & $\begin{array}{l}2 \% \\
\text { chlorhexidindigluconat } \\
\text { stock solution in } \\
\text { distilled water }\end{array}$ & $0.2 \%$ \\
\hline $\begin{array}{l}\text { Povidone-iodine } \\
\text { (Betaisodona }{ }^{\circledR} \text { ) }\end{array}$ & lodine & $\begin{array}{l}\text { Mundipharma } \\
\text { GmbH, } \\
\text { Limburg, } \\
\text { Germany }\end{array}$ & $\begin{array}{l}\text { 10\% povidone-iodine, } \\
\text { glycerol, nonoxinol 9, } \\
\text { disodium hydrogen } \\
\text { phosphate, citric acid, } \\
\text { sodium hydroxide, } \\
\text { potassium iodate in } \\
\text { aqueous solution }\end{array}$ & $10 \%$ \\
\hline $\begin{array}{l}\text { Miramistin } \\
\left.\text { (Miramistin }{ }^{\circledR}\right)\end{array}$ & $\begin{array}{l}\text { Quaternary } \\
\text { ammonium } \\
\text { compound } \\
\text { (QAC) }\end{array}$ & $\begin{array}{l}\text { Farmhim, } \\
\text { Shostka, } \\
\text { Ukraine }\end{array}$ & $\begin{array}{l}0.5 \mathrm{mg} \mathrm{ml}-1 \text { miramistin } \\
\text { powder in distilled } \\
\text { water }\end{array}$ & $0.05 \%$ \\
\hline $\begin{array}{l}\text { Cetylpyridinium- } \\
\text { chloride }\end{array}$ & $\begin{array}{l}\text { Quaternary } \\
\text { ammonium } \\
\text { compound } \\
\text { (QAC) }\end{array}$ & $\begin{array}{l}\text { Sigma- } \\
\text { Aldrich, } \\
\text { Schnelldorf, } \\
\text { Germany }\end{array}$ & $\begin{array}{l}5 \mathrm{mg} \mathrm{ml}-1 \\
\text { cetylpyridinium chloride } \\
\text { in distilled water }\end{array}$ & $0.5 \%$ \\
\hline
\end{tabular}

Due to technical limitations, Table 2 is only available as a download in the supplemental files section.

\section{Figures}




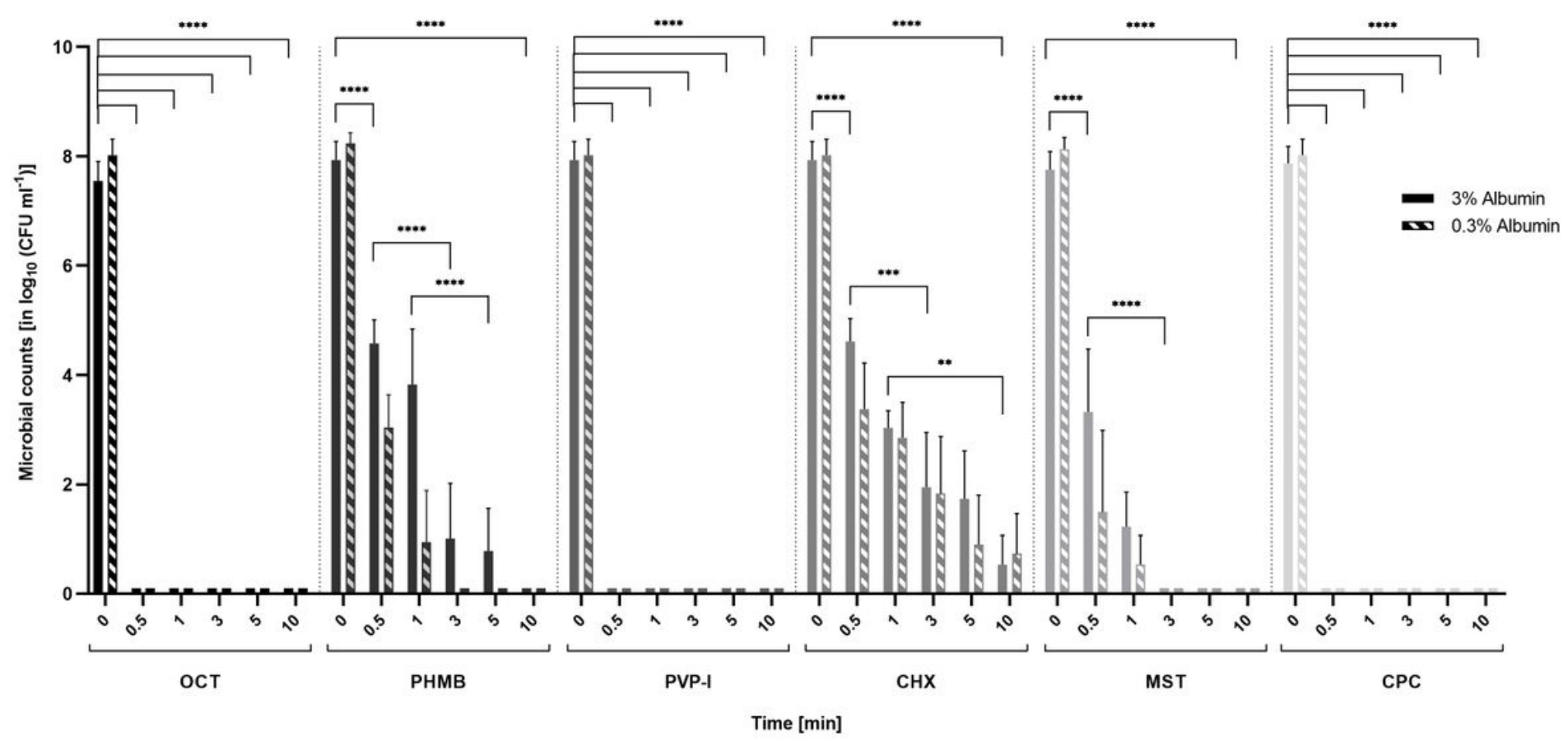

Figure 1

Reduction rates of tested antimicrobials against S. aureus under $0.3 \%$ or $3 \%$ protein-challenge. Microbial counts are expressed as log $10 \mathrm{CFU}$ ml-1 over time. Antimicrobials are displayed individually with a side by side comparison of the reduction rates under $3 \%$ and $0.3 \%$ protein-challenge. OCT, PVP-I and CPC achieved complete reduction of $\mathrm{S}$. aureus after 0.5 min regardless of the challenge. PHMB and MST required longer exposure times to achieve complete reduction and yielded lower reduction rates under high-protein challenge (3\%). $\mathrm{CHX}$ achieved the required $\geq 5$ log reductions, but did not completely eradicate S. aureus (significant reductions over time are indicated as ${ }^{*} p<0.05,{ }^{* \star} p<0.01,{ }^{\star \star *} p<0.001$, $\star \star \star \star p<0.0001)$. 


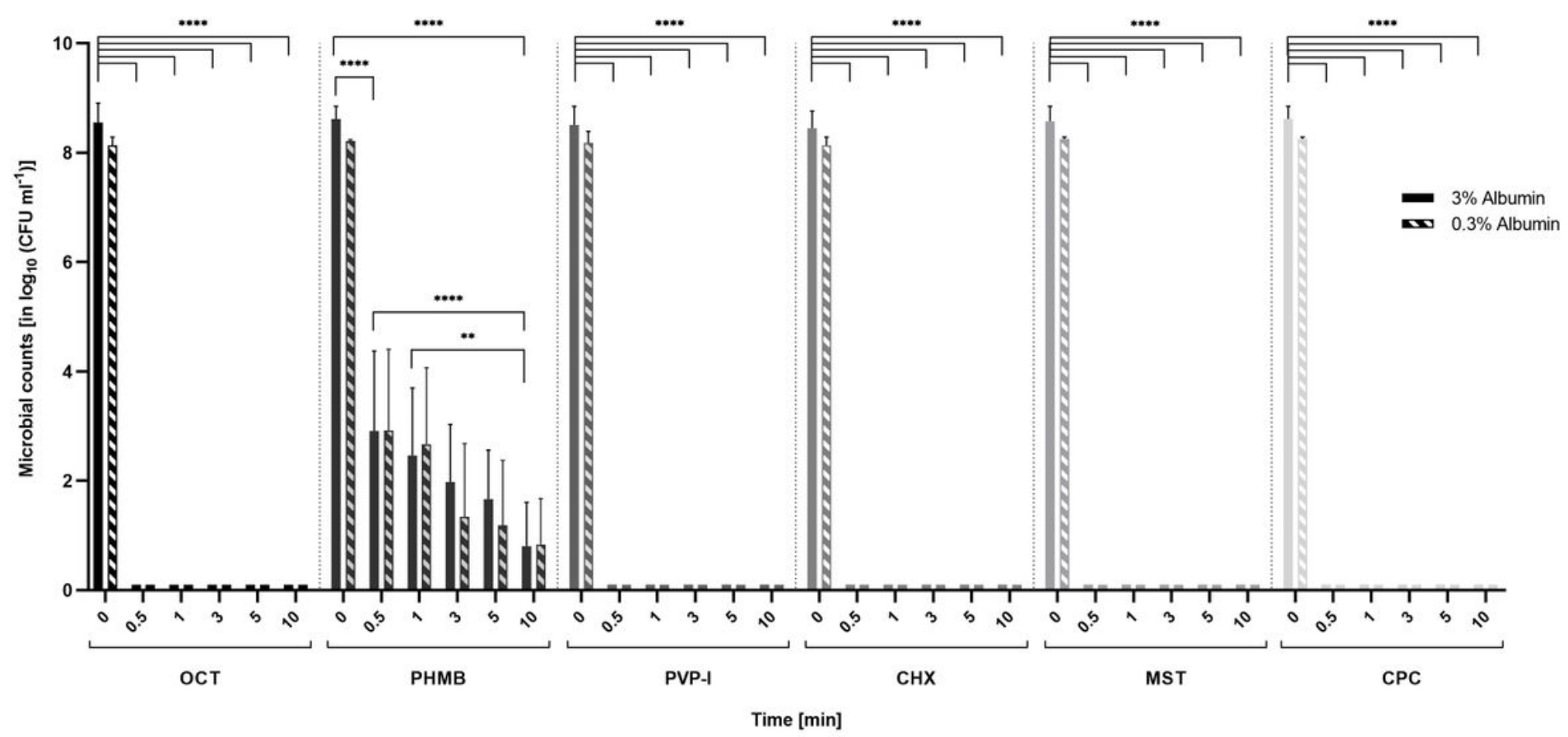

Figure 2

Reduction rates of tested antimicrobials against E. coli under $0.3 \%$ or $3 \%$ protein-challenge. Microbial counts are expressed as $\log 10 \mathrm{CFU}$ ml-1 over time. Antimicrobials are displayed individually with a side by side comparison of the reduction rates under $3 \%$ and $0.3 \%$ protein-challenge. Except for PHMB, all tested antimicrobials achieved complete reduction of $\mathrm{E}$. coli within $0.5 \mathrm{~min}$ of exposure regardless of the challenge. PHMB on the contrary achieved significant and required reductions, but failed to completely eradicate $\mathrm{E}$. coli in these experiments (significant reductions over time are indicated as ${ }^{\star} p<0.05,{ }^{*} \mathrm{p}<$ $0.01, * \star * p<0.001, * \star \star \star p<0.0001)$.

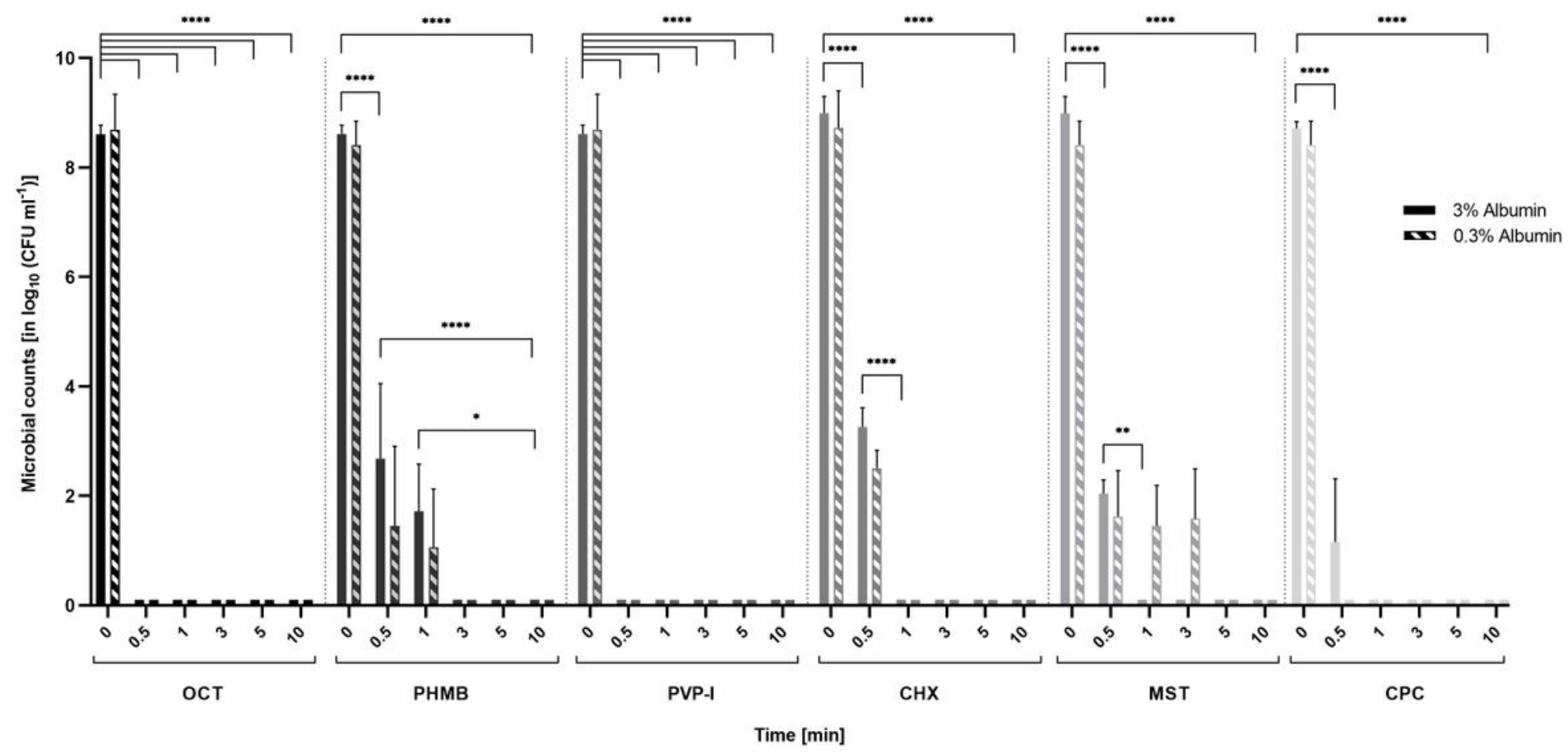




\section{Figure 3}

Reduction rates of tested antimicrobials against P. aeruginosa under $0.3 \%$ or $3 \%$ protein-challenge. Microbial counts are expressed as log10 CFU ml-1 over time. Antimicrobials are displayed individually with a side by side comparison of the reduction rates under $3 \%$ and $0.3 \%$ protein-challenge. OCT and PVP-I achieved complete eradication of P. aeruginosa within $0.5 \mathrm{~min}$. CHX, MST and CPC needed a prolonged exposure time of 1 min under $3 \%$ protein-challenge to achieve full reduction. After 3 min, PHMB also managed a complete eradication of $\mathrm{P}$. aeruginosa (significant reductions over time are indicated as $\left.{ }^{\star} p<0.05,{ }^{* *} p<0.01, * \star * p<0.001, * \star \star * p<0.0001\right)$.

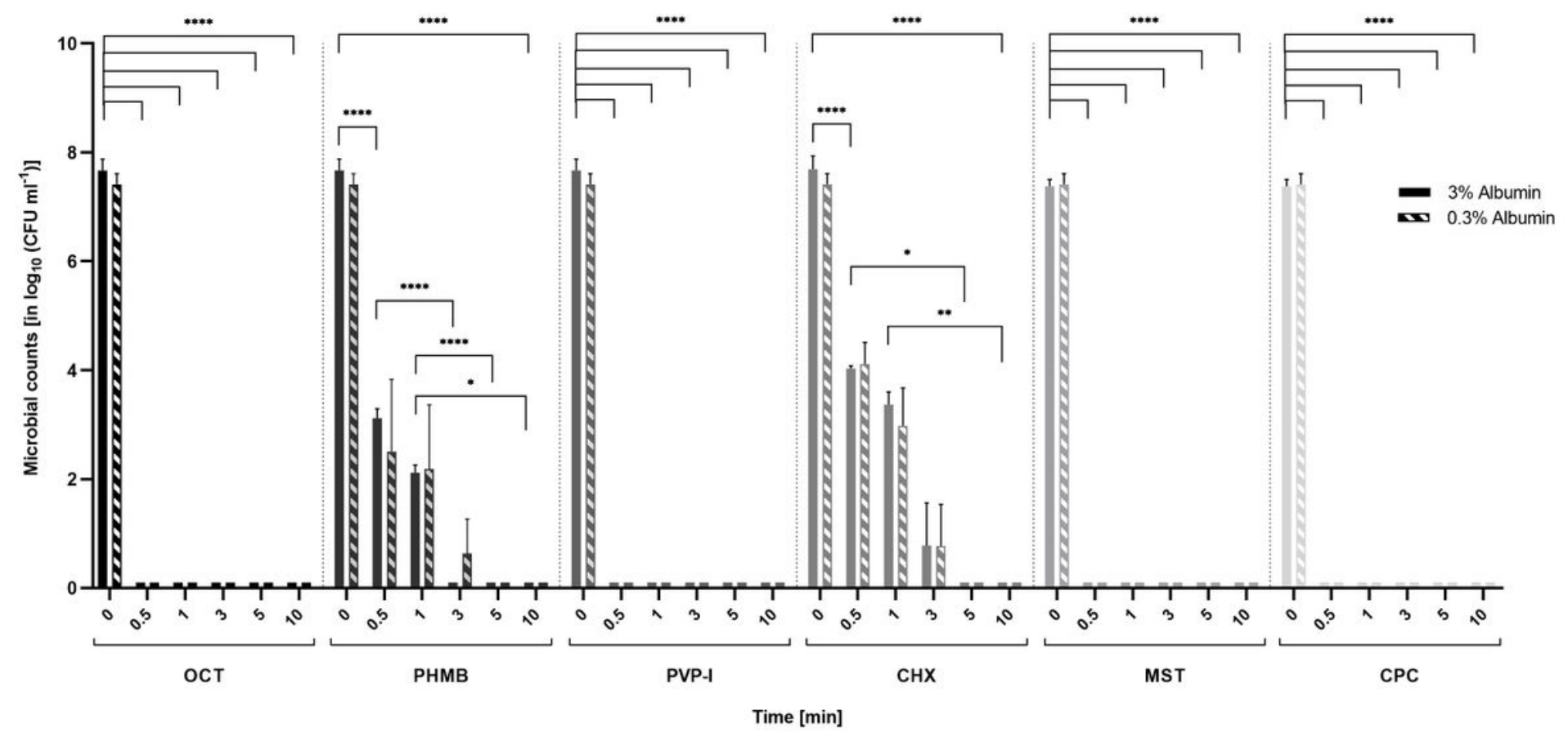

Figure 4

Reduction rates of tested antimicrobials against E. faecium under $0.3 \%$ or $3 \%$ protein-challenge. Microbial counts are expressed as log $10 \mathrm{CFU}$ ml-1 over time. Antimicrobials are displayed individually with a side by side comparison of the reduction rates under $3 \%$ and $0.3 \%$ protein-challenge. OCT, PVP-I, MST and $\mathrm{CPC}$ completely reduced $\mathrm{E}$. faecium within $0.5 \mathrm{~min}$ of exposure. PHMB needed a prolonged exposure time of $3 \mathrm{~min}$ to achieve complete eradication, while $\mathrm{CHX}$ required $5 \mathrm{~min}$. (significant reductions over time are indicated as $\left.{ }^{*} p<0.05, * * p<0.01, * \star \star p<0.001, * \star * * p<0.0001\right)$. 


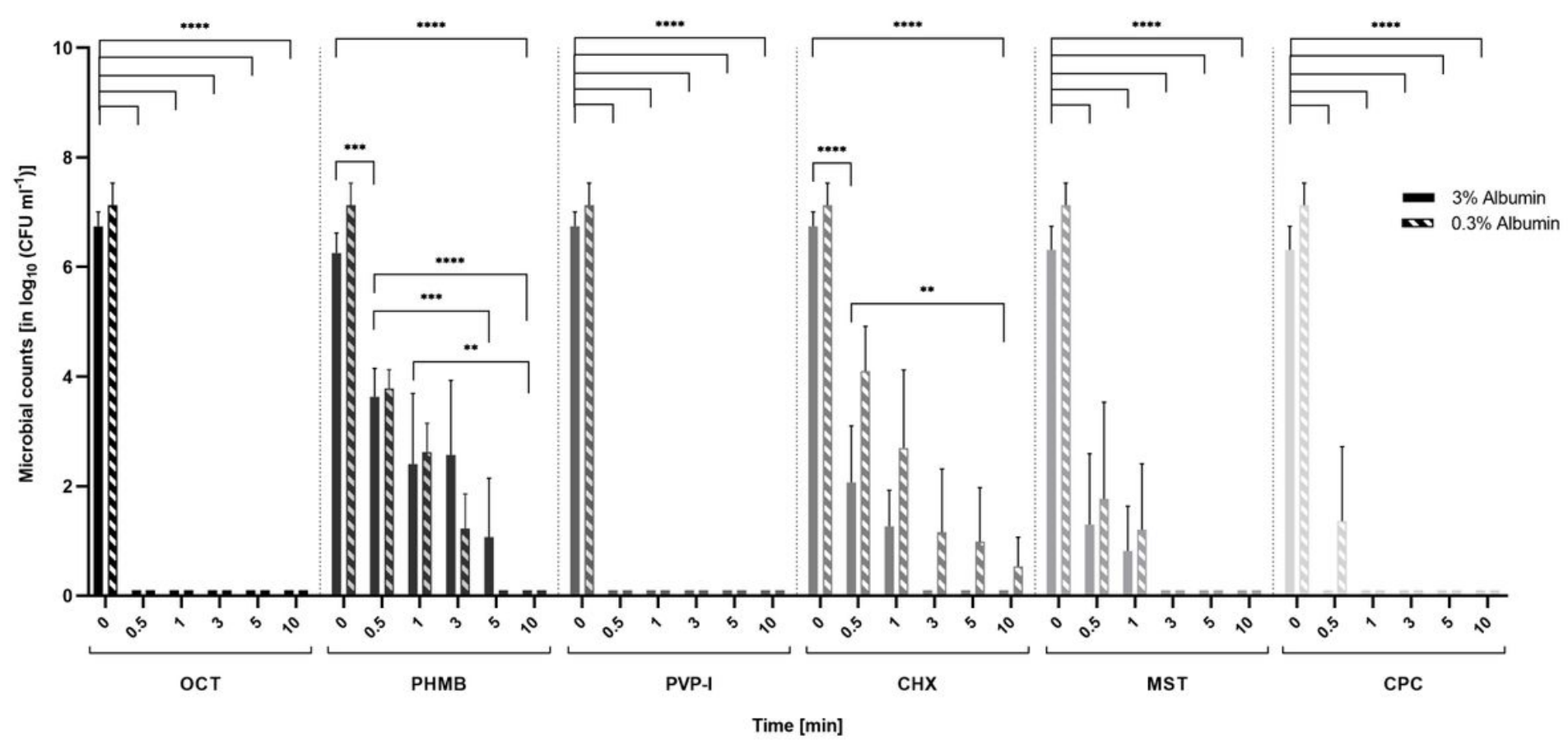

Figure 5

Reduction rates of tested antimicrobials against C. albicans under $0.3 \%$ or $3 \%$ protein-challenge. Microbial counts are expressed as log10 CFU ml-1 over time. Antimicrobials are displayed individually with a side by side comparison of the reduction rates under $3 \%$ and $0.3 \%$ protein-challenge. OCT and PVP-I achieved complete reduction of C. albicans within 0.5 min of exposure. CPC also achieved complete reduction within 0.5 min under high-protein challenge (3\%), but needed 1 min under lower challenge. MST and PHMB needed prolonged exposure times with MST achieving complete reduction within $3 \mathrm{~min}$ and PHMB within $10 \mathrm{~min}$. $\mathrm{CHX}$ did not achieve full reduction of $\mathrm{C}$. albicans within $10 \mathrm{~min}$ (significant reductions over time are indicated as ${ }^{\star} p<0.05$, ${ }^{\star \star} p<0.01,{ }^{\star \star \star} p<0.001,{ }^{\star \star \star \star} p<0.0001$ ).

\section{Supplementary Files}

This is a list of supplementary files associated with this preprint. Click to download.

- supplement1.pdf 